\title{
Consumer Behaviour in Regard to Recycling of Green Secondary Packaging in Kenya
}

\author{
Dr. Hannah Wambugu ${ }^{1 *}$, Dr. Raymond Musyoka ${ }^{2}$ \\ ${ }^{I}$ School of Business and Economics, Kirinyaga University \\ ${ }^{2}$ School of Business Administration, University of Nairobi, Nairobi Kenya
}

*Corresponding Author: Dr. Hannah Wambugu, School of Business and Economics, Kirinyaga University

\begin{abstract}
Kenya aspires to become a middle-income economy by 2030, and as a result the government through NEMA is working extra hard to have a clean environment before then. There has been widespread plastic bags littering throughout the country, and as a result plastic waste issues have attracted widespread concern and attention in Kenya for the last five years. This has rekindled the idea of green marketing right from product/service design, packaging to distribution through retail outlets.A lot of research has been done on effects of characteristics of primary packaging on purchase behaviorin both developed and developing countries. However, from the accessible literature, there is no quantitative teststo show the factors driving post-purchase behavior in respect to recycling of packaging by shoppers in Kenya. This study investigated the effects of packaging characteristics and information processing on shoppers" post-purchase decisions in regard to recycling of secondary packaging in Kenya. Shoppers personal characteristics were controlled, and the study adopted a survey design where a sample of 600supermarket shoppers in three Nairobi metropolitan towns of Kiambu, Ruiru and Thika were interviewed using structured questionnaires. Results were analyzed using regression analysis method, and the results shows indicated that, size have a positive and significant effect on the post-purchase behavior towards green secondary packaging mainly recycling behavior, (coefficient 0. 0.503 p-value $=0.000)$. Graphics had significant effect on recycling behavior (Coefficient 0.264, p-value 0.000). Price had positive and significant effect on recycling behavior (Co-efficient 1.282, pvalue $=0.000$ ). Information related to brand name and logo has positive but insignificant effect on the recycling behavior of green secondary packaging. Technology related attributes (durability) had positive and significant effect on the recycling behavior (Coefficient 1.143, p-value $=0.000$ ). Information processing has positive and significant effect on recycling behavior (Coefficient 0.605, p-value 0.000). Individual Consumer variables except for the gender (Coefficient -040, p-value 0.171) had positive and significant effect on recycling behavior. Knowledge generated in this study is important to the business community in Kenya and the Kenyan government in that, manufacturers and retailers will use it to plan their marketing strategies in order to promote the green marketing agenda, while the government through NEMA will use it as an eye opener when developing policies to guide waste disposal. Based on the results, conclusion can be reached that green secondary packaging is an intervention by NEMA that has contributed to the acceptance of recycling of green packaging and it will go a long way in improving the environment.
\end{abstract}

Keywords: Packaging, Green Secondary Packaging, Post-purchase Behavior, Recycling

\section{INTRODUCTION}

Rapid rate of urbanization throughout the world has led to the generation of increasing amounts of waste, including plastic waste and this in turn poses difficulties for disposal. According to Ambuchi (2006), the problem is more acute in developing countries such as Kenya. As a result, plastic waste issues have attracted widespread concern and attention in Kenya, particularly in the last five years because of widespread littering throughout the country. As Kenya strives to be a middle-income economy by 2030 is also expected to have a clean environment. This prompted NEMA to disturb the status quo that has existed over the years for the manufacturers, distributors and the consumers (users). NEMA argued that the current status of environmental degradation should be blamed on plastic bags that are damned everywhere by Kenyans both in rural and urban areas. This situation has caused a lot of harm to animals, including both terrestrial and aquatic varieties, which eats plastic bags, and suffer from serious health problems. In urban areas, plastic bags cause significant environmental harm because runoff water collects and carries discarded plastic bags and ultimately 
washes them into storm sewers causing clogged sewage systems. This causes serious problem of flooding in Kenyan cities. Flooding water damages property, and it also collects pollutants and spreads them far and wide, where they cause additional damage. The other problem blamed on plastic bags is aesthetic deterioration because plastic bags ruin the appearance of just about every imaginable habitat, from forests and fields to deserts and wetlands (www.greener Ideal, 2018).

The environmental impact of plastic secondary packaging and the drastic step by NEMA to ban them, has made both manufacturers and distributors to think harder about green marketing. Green marketing includes green designing of products, green positioning, green pricing, green packaging and green disposal. Green design is the conceptualization of products that are environmentally-friendly. Green positioning is where a business promotes its sustainability performance, and those of its products and services as a key component of its business activities. Green Pricing is where a company highlights how a green product or service can help consumers save key resources, this being the bases of advising them to pay an extra coin for this benefit. Logistic green is doing away with wasteful and hard-to-open packaging materials such as plastic clamshell casings, wire ties and air-bubble wrap. Green disposal refers to sustainable disposal practices such as recycling. Green packaging is that packaging that cannot biodegrade and does not take up enormous amounts of space in landfills. A business that manufactures and packages products can convert to eco-friendly packaging. Converting to biodegradable packaging provides customers with a visible symbol of the company's commitment to "going green." The business can also leverage the eco-friendly packaging as part of its advertising program to help draw in new environmentally conscious customers (www.greener Ideal, 2018).

This study focuses on green secondary packaging and green disposal, mainly recycling which is a consumers' post-purchase behavior. Secondary packaging should not be confused with logistic packaging, which is packaging that enables manufactures to deliver goods to wholesalers and retailers. Secondary packaging on the other hand is packaging that enables shoppers to move goods from the point of purchase to point of consumption, which is their homes. Green secondary packaging is that packaging whose design and make is environmentally-friendly.

Primary packaging refers to the layer of packaging in immediate contact with a product; in other words, it is the first packaging layer in which the product is contained (Wambugu, 2015). As such, primary packaging is constructed both with the product itself and any existing secondary layers of packaging in mind. The properties of the product (form, dimensions and consistency) evidently dictate the main priorities of primary packaging. Secondary packaging is intended to protect not only the product, but also the primary packaging, which often is the packaging most visible to the consumer in retail displays. The most common examples of secondary packaging include cardboard cartons, cardboard boxes and cardboard/plastic crates (www. Kimberley wats on packaging 2015).

Previous studies on packaging attributes and consumer behavior have focused on consumers' perception of various characteristics of primary packaging (Agniezka \& Miroslaw, 2008; Nelson, Barbara \& Janis, 2006; Wambugu, 2015) and the effect it has on the purchase behavior. From the accessible literature, there is only one study by Ambuchi (2006), which evaluated policies on plastic bags management. This was way back before the ban of plastic bags in Kenya. There is no studies in Kenya that has focused on the effect of green secondary packaging characteristics and consumer individual characteristics on the post purchase behavior in regard to package recycling/re-use effort after the ban of plastic bags. This made it necessary for this areas to be investigated here in Kenya.

This research investigates the determinants of consumer post-purchase behavior in regard to recycling of secondary packaging. Specifically, the study aimed at:

a) Investigating whether size as a visual element of green secondary packaging influences recycling habits of green secondary packaging by consumers in Kenya

b) Determining whether informational attributes (logo and brand name) of green secondary packaging recycling habits of green secondary packaging by consumers in Kenya

c) Investigating whether technological attributes (graphics and design) of green secondary packaging affects recycling habits of green secondary packaging by consumers in Kenya

d) Determining whether information processing influences recycling behavior of green secondary packaging by consumers in Kenya

e) Examining whether consumers' individual characteristics influences recycling behavior of green secondary packaging by consumers in Kenya 
Retailers may benefit from this study in that, the information generated could help them to understand shopper's behavior in regard to recycling of the green secondary packaging. This understanding could assist retailers when planning the expenditures for provision of green secondary packaging in their retail outlets.

To manufacturers of secondary packaging, this study will shed light on packaging characteristics that should be taken into account when designing their packaging. Manufacturers can adjust their packaging accordingly in order to meet customers' needs.

The findings can also assist the government when assessing the success of policies regarding use of secondary packaging. The findings could also guide the government when developing policies for designing and disposal of secondary green packaging in Kenya.

\section{LITERATURE REVIEW}

\subsection{Theoretical Literature}

\subsubsection{Theory of Purchase Decision Process}

The buying process starts when the buyer recognizes a problem or need triggered by internal or external stimuli. With internal stimuli, personal needs such as thirst rises and becomes a need. External stimuli can come from exposure from promotion etc. The second step is information search, and there are several sources of information such as; Personal sources such as family, friends and neighbors; commercial sources such as advertises; public sources such as mass media and consumer organizations; experiential such as handling, examining and using a product.

The third step is evaluation of alternatives, where the consumer processes competitive brand information and makes a final value judgment. At this stage the consumer forms preferences among the brands in the choice set. This leads him to the fourth step where he makes actual purchase of the preferred choice, and exchange of good/service and money takes place. After purchase the consumer experiences the product/service by using it. He moves to the fifth stage- post-purchase stage, where he makes his judgment of the product or service. His judgment will determine his behavior there afterwhether he will do referrals and repeat purchase.

\subsubsection{Theory of Packaging Attributes and Purchase Decision}

Different authors define packaging in different ways. Arens (1996 p.g 57) defines package as 'a container for a product', which encompasses the physical appearance of the container and it includes the design, color, shape, labeling and materials used. According to Cateora \& Graham (2002), packaging is an integral part of the product element of the 4 Ps of the marketing mix: product, price, place and promotion. Young (2003 p.g 19) in his part defines packaging as 'the wrapping material around a consumer item that serves to contain, identify, describe, protect, display, promote and otherwise make the product marketable and keep it clean' (Aaker, 2005 p.g 13), defines package 'as an attribute that is not related to the product, which includes the logo and or/graphic symbol, the personality and the slogans'. According to Paul \& James (2007 p.45), package is an extrinsic element of the product, an attribute that is related to the product but does not form part of the physical product itself. Saleemi, (2011p.g 250) defines packaging as 'the general group of activities in product planning which involves designing and producing the container or wrapper for a product'.

Dhruv \& Michael (2008) identifies various types of modern packaging which include: Flexible packaging which involves use of flexible materials such as foils and films. Rigid packaging retains the shape through normal conditions, and involves the use of rigid materials such as plastics, glass, metal, wood and clay. Other types of modern packaging identified by (Bix et al, 2003) includes; semi-rigid packaging which involves the use of materials such as paper boards, corrugated boards and cloth like or nylon sacks-like packaging; industrial packaging, which is the packaging for industrial goods but could also be used to pack durable goods such as cookers, radios and refrigerators. Interior is another type of packaging, which is protective packaging within a package using shock-absorbing materials and dividers.

Packaging has two dimensional functions (Saleemi, 2011). First it must protect the product from damage during transportation. It also has promotional role which has become more important. In general, packaging plays the following roles: Assembling and arranging the contents in desired form, Identifying the content, the brand and the make, protecting the contents from production line through final use, providing a suitable product mix including sizes, weights, prices grades and package, 
facilitating retailer's functions, facilitating transportation, storage and warehouse handling, assists in displaying of contents helps in complying with legal requirements and finally providing opportunity and space for adverting.

According to Kotler et al, (2009), although protection, convenience and economy remains the traditional purposes attached to package, in the recent time, the fourth objective has received increasing recognition from the manufacturers. This is designated as promotional function (Dileep, 2007), and the reasons for its increased importance includes: the increased use of self-service methods of selling, where packaging is being used to attract attention, describe the product features, give consumer confidence and make a favorable overall impression. Another factor responsible for giving this new dimension to packages is the consumer difference. Prestige of a product is maintained with the help of packaging. Good packaging is capable of projecting various qualities of the product as well as the manufacturers (Smith \& Tylor, 2004).

Packaging is a vehicle for communicating and branding a product. Characteristics of the package provide cues which make the consumer either select or not select a product (Kibera \& Waruingi, 2007). Among the product attributes, packaging carries all the other variables, that is: the price, brand name, color. There have been arguments in regard to the number of packaging characteristics that are available to both designers and consumers (Rita et al, 2009). For example, according to Kotler, et al, (2009), the six elements of consumer packaging that must be considered when designing package are size, form, material, color, text and brand. Each of these packaging attributes plays a different role in influencing consumer purchase decision. According to Silayoi \& Speece (2004), the six elements that must be taken into account by manufacturers and designers in order to come up with efficient package include: size, color, graphics material and flavor. However the thinking of (Smith et al, 2004) have been be criticized in that flavor is part of the product, it can only be expressed through packaging by choosing the right color and graphics (Rita et al, 2009).

According to Silayoi \&\& Speece (2004), the six packaging attributes are grouped into two categories: visual and informational elements. The visual characteristic consists of graphics, size, color and shape of packaging. These characteristics relate more to the affective side of decision-making. Informational elements relate to information provided and technology used in the package. These elements are more likely to address the cognitive side of decisions. Informational elements require more mental effort to process than visual elements, and the latter usually evoke more of an emotional response.

Consumer behavior towards products is characterized by different stages of decision making process Kibera \& Waruingi, (2007). Based on this theory, Esitri et al (2010) was for the view that the influence of packaging attributes should be analyzed depending on the stage of purchase decision. He argued that, the same attribute could be more important in one stage than in another (Estiri et al, 2010).

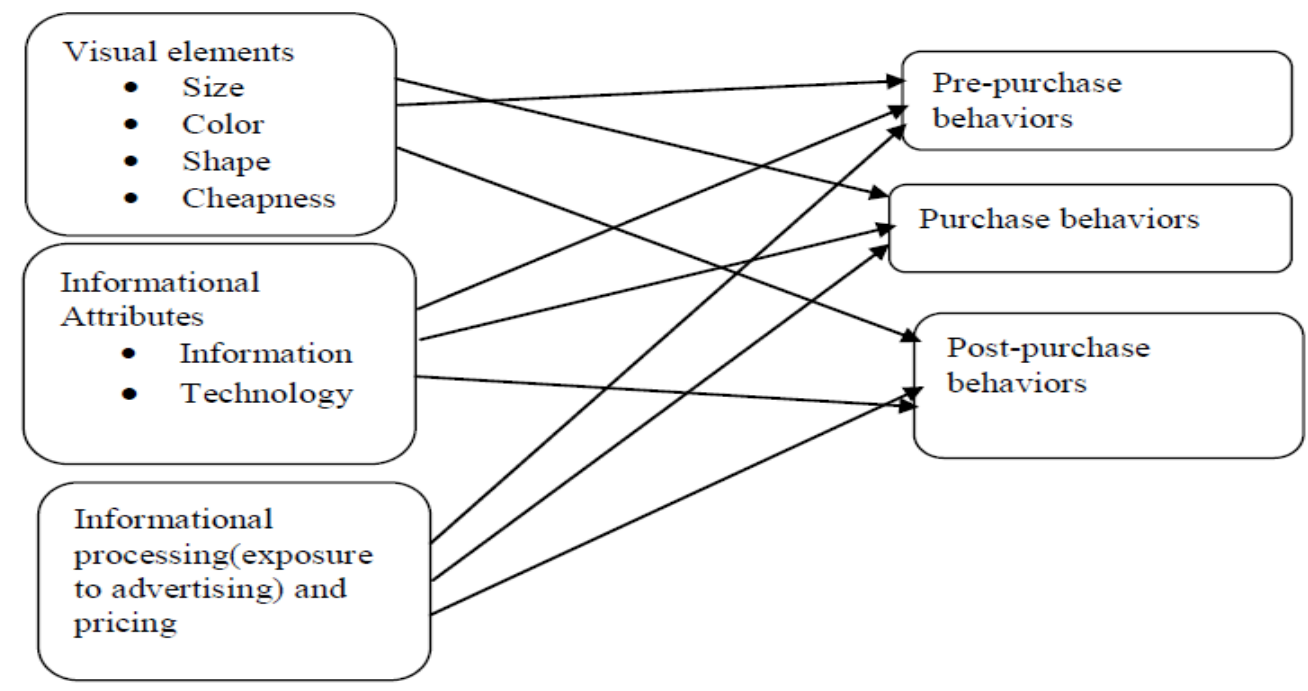

Figure1: Packaging Attributes, information processing and Consumer Purchase Decision

This study borrowed partially from the above model. The reason being that, the study focused only on the post-purchase behavior of consumers in regard to recycling of green packaging bags. According to this model visual elements include: size, aesthetics (shape and color) and cheapness. Technology 
elements included functional attributes and durability. Informational attributes included brand name and slogan. The model was extended to include information processing since it can influence consumer behavior in the three stages of purchase decision process.

\subsubsection{Theory of individual Characteristics on Buyers' Decision Making}

Individual circumstances tend to stem from demographic characteristics such as income, education, and age.

Gender - Mainly due to social norms, many of which can be traced back for centuries, men and women tend to buy different types of products and use different criteria when choosing what to buy. By identifying the behavioral differences between the sexes, marketers can reach huge untapped markets whose needs have never been fully satisfied (Liz \&Terry, 2004).

Age- It determines some of the buying decisions people make. Consumer preferences for styles, fashions and the products they purchase changes with age. Manufacturers of certain products and services emphasize these differences in their brand names and promotional campaigns (Liz \&Terry, 2004).

Income -An individual's disposable income can vary for many reasons, in particular due to higher interest rates, unemployment or inflation. Certain products and services are more income sensitive than others. If the income of consumers is reduced, they usually cut down their expenditure on durables and leisure, and their buying decisions at this particular time are likely based on functionality of the product other than the style and design (Liz \&Terry, 2004; Kibera \& Waruingi 2007)

Education -Levels of education are usually related to income and social class but have other interesting influences on consumer behavior. Primary school drop outs tend to make their purchasing decisions on the basis of tradition, brand image and personal experience unlike consumers with secondary education and above. For this category of consumers, manufacturers emphasize reliability and corporate image, unlike with the latter category where apart from durability, they provide detailed explanations and justifications (Liz \&Terry, 2004).

\subsubsection{Theory of Information Processing and the Price}

Information Processing- Consumer's information processing has to do with exposure to a product through advertising and other promotional means. Such exposure helps in attracting consumers' attention, arousing their interest and stimulating their desire in order to encourage action of purchase. Advertising also informs the consumers about the price, product characteristics and where to find the product.

Price- Price is one of the most important and far-reaching of the variables that marketing managers control. Pricing decisions affects profit, volume, share of the market and social stance. When setting the price of products and services, manufacturers must take into account internal and external factors. The key to pricing success is the attractiveness of price to the consumer, not forgetting that prices of goods and services carries image connotations for brands.

\subsection{Empirical Literature}

Several studies have been done on the effect of packaging characteristics on consumer behavior. Judy, Stuart \& Antonio (2003) investigated the impact of color and other packaging attributes as stimuli in decision making process for low involvement products. In this study, a constant sum scale of out of a 100 was used to rate attributes of information about flavor and quality, logo, price size, shape and color of packaging. The results indicated that all packaging characteristics except for color were significantly important when buying a product. Arranged according to order of importance, flavor was the most important attribute, flowed by quality, brand/ logo and price in that order.

Silayoi \& Speece (2004) investigated the impact of involvement level during purchase and time pressure on the importance of packaging characteristics. The importance of packaging was measured using Likert scale of 1 to 5. The two factors were found to positively influence the overall importance of packaging characteristics. The study was limited in that it included only one situational factor being time constrained, yet there are five categories of situational factors.

Bytyqi, Gjonbalaj, Mehmeti, Gjergjizi, Miffari \& Njazi (2008), investigated the buying behavior in regard to dairy products in Kosovo. The perception of consumers about dairy products was assessed using variables such as the origin of the product, price, quality as indicated on the label, package, place of purchase age of the consumer, gender of the consumer, and brand/logo. Although all the 
packaging characteristics were found to be significantly important, logo and price were found to be the most significant attributes of packaging for dairy products. Shopping location was not significant. Agniezka \& Miroslaw (2008) analyzed the effect of individual characteristics on the importance of packaging characteristics for dairy products in Turkey. The study found that packaging form, aesthetics, size, capacity, material and cheapness was significantly important when selecting milk packages. The results also indicated that while men perceive packaging material as an important packaging characteristic women did not. Concerning the importance of package size and usage, the study found that there was significant correlation in case of gender, education and income. In case of women, package size played an important role for purchase decision compared to men. Durability of the material was significant and environmental considerations were significant.

Rita et al, (2009) investigated the impact of both visual and verbal elements of package on the consumer. Both elements were found significantly important. Size element was the most important visual element for purchasing milk. Color though important, was not perceived as very important in relation to others. Another element which was perceived as less important is the graphics and the logo, but product information was perceived important. Rita et al (2009) also investigated impact of these package elements for consumers shopping under time pressure and those not shopping under time pressure. The study found that informational (verbal) package elements are more important than visual situation in both situations.

Estiri et al, (2010) examined the relationship between consumer behaviors towards packaging elements of food products and socio-economic status of consumers in Refah chain stores in Iran. The study evaluated and compared the effects of packaging elements on consumer behavior in the prepurchase, purchase and post-purchase stages. The results showed that the packaging characteristics are significant in all stages of purchase decision. The results also indicated that consumers' gender has significant impact on size, shape and information variables. For female consumers, at pre-purchase stage color and shape, at purchase stage size and shape and at post purchase information and size are important. On the other hand, for male consumers at pre-stage purchase information and shape, at purchase stage color and information and at post purchase stage color and shape are more important.

Karin et al, (2010), examined the consumer perception of food packaging based on the importance given to different functional attributes. These include packaging being purposive, recyclable, informative and attractiveness, quality and hygienic. The study found that consumers perceived packaging characteristics that reflected quality, shelf life attribute, functional attributes and packaging environmental friendliness were important to consumers.

In conclusion all those studies concentrated on the characteristics of primary packaging that was in contact with the product. None of those studies touched on the secondary packaging and whether it was recycled, and the factors that motivated shoppers to re-cycle secondary packaging.

\section{Conceptual Frame work}

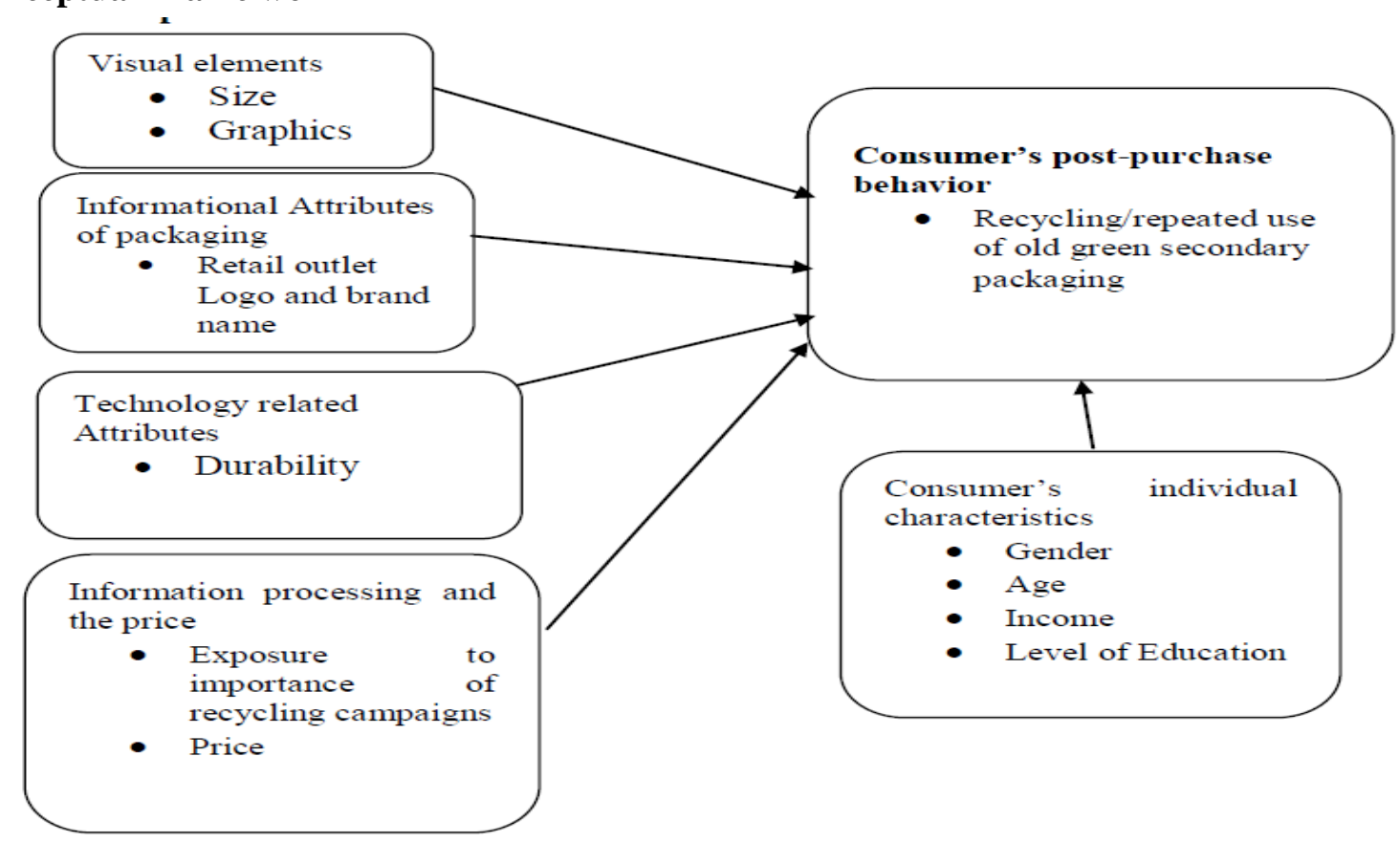




\section{MeTHOdOLOGY}

This study was designed in form of a survey, where 600 shoppers were interviewed on how many times they recycle one type of green secondary packaging introduced in Kenya recently per month. The sample was randomly selected at the entry of five supermarkets in the metropolitans' towns of Thika, Ruiru and Kiambu. The data collected was analyzed using regression analysis.

The following multiple regression model was constructed to find out whether there is any significant relationship between the numbers of times green secondary is recycled by consumers and packaging characteristics. The specified multiple regression model was estimated using the method of ordinary least squares. This model is appropriate because in this study, the dependent variable is continuous. The model is presented as follows:

$$
\begin{aligned}
Y= & \alpha_{0}+\alpha_{1} X_{1 i}+\alpha_{2} X_{2 i}+\alpha_{3} X_{3 i}+\alpha_{4} X_{4 i}+\alpha_{5} X_{5 i}+\alpha_{6} X_{6 i}+\alpha_{7} X_{7 i}+\alpha_{8} X_{8 i}+\alpha_{9} X_{9 i} \\
& +\alpha_{10} X_{10 i}+u_{i}
\end{aligned}
$$

Where: $Y=$ number of times packaging is recycled, $\alpha_{0}=$ constant term. $\alpha_{1}, \alpha_{2} \ldots \ldots \ldots \ldots \alpha_{16}$ are unknown parameters associated with changing patterns of the explanatory variables which must be estimated. The explanatory variables are: $X_{1}=$ size of green secondary packaging $X_{2}=$ graphics, $X_{3}$ $=$ price of green secondary packaging, $X_{4}=$ information related to brand name and logo, $X_{5}=$ technology attributes(durability) $X_{6}=$ Information processing $=X_{7}=$ shopper's age, $X_{8}=$ shoppers' education, $X_{9}=$ shopper's gender, $X_{10}=$ Monthly income and $u_{i}=$ random error term.

\begin{tabular}{|c|c|}
\hline Size of green secondary packaging & Size $=1$ if Large,$=$ and size $=0$ if small \\
\hline Graphics & Graphics $=1$ if present $=0$, if without graphics \\
\hline Price & Amount paid in Kenya shillings \\
\hline Information & $\begin{array}{l}\text { Information }=1 \text { if it has brand name and } \log 0,=0 \text { if without } \\
\text { brand name and logo }\end{array}$ \\
\hline Technological element & Technological $=1$ if durable,$=0$ if non-durable \\
\hline Information processing & $\begin{array}{l}\text { Information processing }=1 \text { if with high exposure to } \\
\text { importance of recycling campaigns, }=0 \text { if with low exposure } \\
\text { to importance of recycling }\end{array}$ \\
\hline Shoppers' age & Number of years \\
\hline Education & Number of years spent in school \\
\hline Gender & Gender $=1$ if Male, $=0$ if female \\
\hline Income & Amount in Kenya shillings \\
\hline Recycling Behaviour & $\begin{array}{l}\text { Number of times the consumer has recycled the green } \\
\text { secondary packaging }\end{array}$ \\
\hline
\end{tabular}

The variables were operationalized as follows:

\section{RESULTS AND IMPLICATIONS}

80 percent of the respondents had large green secondary packaging, 64 percent had packaging with graphics and 80 percent of all the respondents felt that that those packaging were expensive compared to what they were paying for plastic secondary packaging. 66 percent of the respondents were using green secondary packaging which were not branded. 67 percent had secondary packaging that were considerably durable, while 85 percent were informed of importance of recycling secondary packaging.

\subsection{Regression Results}

\begin{tabular}{|l|l|l|l|l|}
\hline Linear & Regression & Number of obs & $=$ & 600 \\
\hline & & F( 9, 591) & $=$ & 232.84 \\
\hline & & Prob $>$ F & $=$ & 0 \\
\hline & & R-squared & $=$ & 0.820 \\
\hline & & Adj R-Squaired & & 0.799 \\
\hline & & Root MSE & $=$ & 0.4188 \\
\hline & Coef & Std.Err & \multicolumn{1}{c|}{ t } & P>t \\
\hline Size of secondary packaging & 0.998 & 0.0403 & 24.99 & 0.000 \\
\hline
\end{tabular}




\begin{tabular}{|c|c|c|c|c|}
\hline Graphics & 0.264 & 0.0275 & 9.62 & 0.000 \\
\hline Price of secondary packaging & 1.282 & 0.0501 & 25.6 & 0.000 \\
\hline Informational Attributes & 0.050 & 0.0171 & 1.29 & 0.169 \\
\hline Technology attributes & 1.143 & 0.030 & 4.71 & 0.000 \\
\hline Information processing & 0.605 & 0.038 & 2.79 & 0.000 \\
\hline Shopper's Gender & 0.040 & 0.025 & 1.31 & 0.171 \\
\hline Shopper's age & 0.573 & 0.002 & 33.4 & 0.001 \\
\hline Shopper's years of education & 1.279 & 0.006 & 25.51 & 0.002 \\
\hline Income & 1.104 & 0.0302 & 23.01 & 0.000 \\
\hline cons & 0.6738 & 0.0961 & 34.49 & 0.000 \\
\hline
\end{tabular}

The Results indicates that, R-squared is equal to 0.820 while adjusted R-squared is equal to 0.799 . This implies that there is high degree of goodness of fit of the regression model. It also means that over $79.9 \%$ of variation in the dependent variable can be explained by the regression model. The $\mathrm{F}$ test result was F $(9,591) 232.84$, with a significance of 0.000 . Consequently, the hypothesis that all regression coefficients in the model are zero is rejected. Therefore, a significant relationship was present between recycling and the explanatory variables in the regression model. RMSE which is the square root of the variance of the residuals or the standard deviation of the unexplained variation was 0.4188 . This was low given that it is below 0.500 , which was an indication that there is high degree of goodness of fit of the regression model.

Results shows that size have a positive and significant effect on the post-purchase behavior towards green secondary packaging mainly recycling behavior, (coefficient $0.0 .503 \mathrm{p}$-value $=0.000$ ). This implied that holding all other factors constant, the number of times the shopper recycles green secondary packaging is expected to be higher by 0.998 times. Graphics had significant effect on recycling behavior (Coefficient0.264, p-value 0.000). Price had positive and significant effect on recycling behavior (Co-efficient 1.282, p-value $=0.000$ ), implying that the number of times the shoppers recycles the green secondary packaging is expected to increase by 1.2 times if the price of packaging is increased by 1 Kenya shillings. Information related to brand name and logo has positive but insignificant effect on the recycling behavior of green secondary packaging. Technology related attributes (durability) had positive and significant effect on the recycling behaviour (Coefficient 1.143 , p-value $=0.000$ ), which implies that the number of times shoppers recycles green secondary packaging is expected to be higher by about 1.143 times for shoppers with durable packages than for those with non-durable green packaging. Information processing has positive and significant effect on recycling behavior (Coefficient 0.605, p-value 0.000), which implies that the number of times shoppers recycles green secondary packaging is expected to be higher by about 0.605 times for shoppers with high exposure to importance of recycling green packages than for those without exposure. All individual characteristics except for the gender (Coefficient -040, p-value 0.171) had positive and significant effect on recycling behavior.

\section{REFERENCES}

[1] Agniezka, K. \& Miroslaw, G. (2008), Package Preferences of liquid Dairy Products Buyers, Economics Journal 2008, vol. $3(2)$

[2] Ahmed, A.N. \& Salman, A. (2005), Critical Issues in Packaged food Business, Brand Food Journal, 107: 760-780

[3] Blackwell, R. D., Miniard, P.W.\& Engel, J. F. (2009), Consumer Behavior $9^{\text {th }}$ Edition, Cengage Learning Products, McGraw-Hill; Harcourt College Publishers, London

[4] Bytygi, H., Vegara, M., Gjonbalaj, M., Mehmeti, H., Gjergjizi H., Miffari I. \& Njazi,B. (2008), An analysis of Consumer Behaviour in regard to Dairy Sector in Kosovo: Retrieved from http://www. studymode.com/essays/Analysis-Of-Consumer-Behaviour-In-Regard-To-Dairy-Products-In-Kosovo441677.html;_Visited on 12th May 2013

[5] Dhruv, G. \& Michael, L. (2008), 'Marketing Tata' McGraw-Hill Publishing Company Limited, New Delhi ISBN 978-0-07-066711-2: 290-294

[6] Dileep, K. M. (2007), Role of Packaging in Marketing Product and Organizations. www.indianmba.com/ faculty-column/Fc337.html. Visited 13th May 2013.

[7] Estiri, H. \& Yazdani, N., (2010), Food products consumer behaviors: The role of packaging elements. Journal of Applied Sciences, 10: 535-543

[8] Judy, R., Stuart, W., \& Antonio, L. (2003), An Exploratory Study into the Impact of Color and Packaging as Stimuli in decision making process for Low Involvement Non-durable Products; Conference Paper, Faculty of Business and Enterprise, Swinbure University of Tecnology, Newzealand 
[9] Kardes, F. R., Maria, C.L., \& Thomas, W. (2011), Consumer Behavior, Mason, OH: South-Western, Cengage Learning

[10] Kibera, F. N. \& Waruingi, B.C. (2007), Fundamentals of Marketing:An African Perspective. Kenya Literature Bureau, Nairobi

[11] Kotler, P., Keller, K. L., Koshy, A. \& Jha, M. (2009), Marketing management, $13^{\text {th }}$ Asian, Perspective, Edition Prentice-Hall London

[12] Liz H. \&Terry, O. (2004), Foundation Marketing, Third Edition; Prentice Hall, ISBN 0273655329

[13] Paul, J. P. \& James, H. D. (2007), Marketing Management, $8^{\text {th }}$ Edition McGraw-Hill Irwin.ISBN-10-0-07313763-4

[14] Rita, K., Aiste D., \& Laura, N. (2009), Impact of Package Elements on Consumer Purchase, Journal of Economics and Management Vol.14:441-447

[15] Saleemi, N.A. (2011) Marketing simplified, Saleemi Publications Ltd, Nairobi, Kenya.

[16] Silayoi, P. \& Speece, M., (2004), Packaging and Purchase Decisions: An Exploratory Study on involvement level and Time Pressure. British Food Journal vol.106 (8):607-628

[17] Young, S. (2003), 'Winning at Retail', Research Insight to improve the Packaging of Children's Products; Young Consumers, Vol. 5(1):17-22

[18] www. Kimberleywatsonpackaging 2015

[19] www.greener Ideal, 2018.

\section{AUTHORS' BIOGRAPHY}

Dr Hannah WanjikuWambugu, Currently a Lecturer and Dean School of Business and Economics, Kirinyaga University. She holds a PhD in Business Administration (Marketing Option)

Dr Raymond Musyoka, Currently a Senior Lecturer at School of Business of the University of Nairobi. She holds a PhD in Business Administration (Marketing Option)

Citation: Dr. Hannah Wambugu. "Consumer Behaviour in Regard to Recycling of Green Secondary Packaging in Kenya" International Journal of Managerial Studies and Research (IJMSR), vol 6, no. 12, 2018, pp. 10-18. doi: http://dx.doi.org/10.20431/2349-0349.0612002.

Copyright: (C) 2018 Authors. This is an open-access article distributed under the terms of the Creative Commons Attribution License, which permits unrestricted use, distribution, and reproduction in any medium, provided the original author and source are credited. 